\title{
Decentration of the Posterior Chamber Lens Implant: the Effect of Optic Size on the Incidence of Visual Aberrations
}

\author{
PETER J. MCDONNELL, DAVID J. SPALTON and MICHAEL G. FALCON \\ London
}

\begin{abstract}
Summary
Intraocular lens implant components such as dialling holes can cause disabling symptoms when decentration of the implant places these components in the pupil. In order to investigate the importance of optic size in this context, we studied two groups of consecutive patients who had undergone cataract surgery: one group had received an implant with a $6 \mathrm{~mm}$ diameter optic, and the other an implant with a $7 \mathrm{~mm}$ diameter optic. We found that there was a significantly higher incidence of implant components such as dialling holes in the pupil in the $6 \mathbf{~ m m}$ group when compared to the $7 \mathrm{~mm}$ group. The incidence of symptoms such as monocular diplopia and glare was marginally but not significantly higher in the $6 \mathrm{~mm}$ group. To minimise the risks of symptoms related to dialling holes in the pupil we recommend an implant design that has a large optical clear zone of at least $6 \mathrm{~mm}$.
\end{abstract}

Current techniques of extracapsular cataract surgery and insertion of a posterior chamber lens implant usually result in excellent vision for the patient. It is therefore distressing for both the patient and the surgeon when occasional problems occur.

One cause of dissatisfaction is visual aberration related to components of the intraocular lens. These problems are rare but may be very disabling, and treatment with miotics may be necessary: in extreme cases surgical removal and replacement of the lens may be indicated. ${ }^{1}$

Many patients are, however, uncomplaining and it is possible that the incidence of visual problems due to implant components could be higher than realised. We decided to investigate whether the presence of components such as dialling holes in the pupil, made more likely by lens decentration, was a com- mon finding in the long term after surgery, and whether this was the cause of any visual problems. We also assessed whether the use of a larger sized optic lens implant with smaller dialling holes had reduced the incidence of such problems.

With these aims in mind we performed a retrospective study of two groups of patients who had undergone cataract surgery at St Thomas's, Hospital.

\section{Patients and Methods}

The names of 134 patients were obtained from the operating theatre records. All patients had undergone extracapsular cataract extraction followed by insertion of a posterior chamber lens implant. None of these patients was recorded as specifically having an endocapsular or 'in the bag' technique and it is likely that many of the implants were fixated in the cili- 
ary sulcus. Sixty-seven consecutive patients received an implant with an optic $6 \mathrm{~mm}$ in diameter, and 67 consecutive patients received an implant with an optic $7 \mathrm{~mm}$ in diameter. The $6 \mathrm{~mm}$ lens in the study was an Iolab $107 \mathrm{~W}$ reverse optic Sinskey-style implant with four $0.4 \mathrm{~mm}$ dialling holes (optical clear zone $=4.40 \mathrm{~mm}$ in diameter), and the $7 \mathrm{~mm}$ lens was an Iolab G756B with two $0.3 \mathrm{~mm}$ dialling holes, and a laser ridge (optical clear zone $=5.36 \mathrm{~mm}$ in diameter).

All patients had undergone surgery during the period April 1987 to August 1988 giving a minimum follow-up of ten months. Exclusions from the study included 28 patients whose medical records were unavailable, three patients who had died, 19 patients whose vision was worse than $6 / 12$ due to other ocular pathology (this included posterior capsular opacity), and 20 patients who failed to reply to the request to attend for assessment. At the end of the study 29 patients with a $6 \mathrm{~mm}$ IOL and 35 patients with a $7 \mathrm{~mm}$ IOL had been examined making a total of 64 patients in the study.

All patients were asked about any visual problems in the operated eye, and they were specifically asked about the presence of glare, monocular diplopia, ghosting of images, and problems with vision while night driving.

On examination visual acuity and current spectacle correction were assessed. When appropriate, retinoscopy was performed. The pupil size was measured using the variable length calibrated slit beam of a Haag-Streit slit lamp under conditions of bright and dim illumination. Bright illumination was with the slit beam at its maximum width shone directly into the pupil and dim illumination was using the thinnest possible slit beam with the green filter in place shone obliquely onto the pupil in a darkened examination room. The presence of dialling holes or the implant edge in the pupil was noted in bright light and dim illumination: the lighting conditions were the same as for assessment of pupil size but in dim illumination a slightly wider beam was needed so that any dialling holes present in the pupil were visible. The pupil was then dilated and the posterior capsule and macula were examined.

A Kowa fundus camera was then used to take axial anterior segment photographs which showed the implant against a red reflex. These photographs were then projected onto a screen so that the horizontal limbal diameter matched a circle $23 \mathrm{~cm}$ in diameter drawn on the screen. This gave a magnification factor of 20 (average horizontal limbal diameter is $11.5 \mathrm{~mm}$, multiplied by $20=23 \mathrm{~cm}$ ). The amount of decentration was then measured and the figure obtained divided by 20 to give the amount of decentration in $\mathrm{mm}$.

\section{Results}

The mean age was 72.4 years for the $6 \mathrm{~mm}$ implant group, and 69.2 years for the $7 \mathrm{~mm}$ implant group; paired t-test showed no significant difference between the ages for the two groups $(p=0.1588)$. The mean post-operative follow-up was 22.4 months for the $6 \mathrm{~mm}$ group and 16.6 months for the $7 \mathrm{~mm}$ group. The shorter follow-up for the $7 \mathrm{~mm}$ group was because overall there were fewer patients at St Thomas's Hospital receiving this size of implant and the consecutive series thus took longer to complete. Every patient initially declared that they had no problems with their vision. It was only on direct questioning that these symptoms were elicited. In the $6 \mathrm{~mm}$ group six patients were found $(21 \%$ of the total) with three seeing a ghosting of images and three seeing glare. In the $7 \mathrm{~mm}$ group five patients were found ( $14 \%$ of the total) with four seeing glare and one a halo around lights. Paired t-test showed that the difference in incidence between the two groups was not statistically significant ( $p=0.3259)$.

Mean pupil size in bright illumination was $2.71 \mathrm{~mm}$ in the $6 \mathrm{~mm}$ implant group and $2.6 \mathrm{~mm}$ in the $7 \mathrm{~mm}$ implant group $(p=0.1585)$, and in dim illumination was $5 \mathrm{~mm}$ in the $6 \mathrm{~mm}$ implant group and $4.8 \mathrm{~mm}$ in the $7 \mathrm{~mm}$ implant group $(\mathrm{p}=0.3737)$.

The mean decentration of the IOL was $0.82 \mathrm{~mm}$ with a range of 0 to $2.25 \mathrm{~mm}$ for the $6 \mathrm{~mm}$ group, and $0.74 \mathrm{~mm}$ with a range of 0 to $2.50 \mathrm{~mm}$ for the $7 \mathrm{~mm}$ group. There was no significant difference in the decentration of the two groups $(\mathrm{p}=0.8082)$.

How many patients had dialling holes visible in the pupil? In the $6 \mathrm{~mm}$ group 7 patients $(24 \%)$ had dialling holes or the edge of the IOL visible in the pupil during bright 


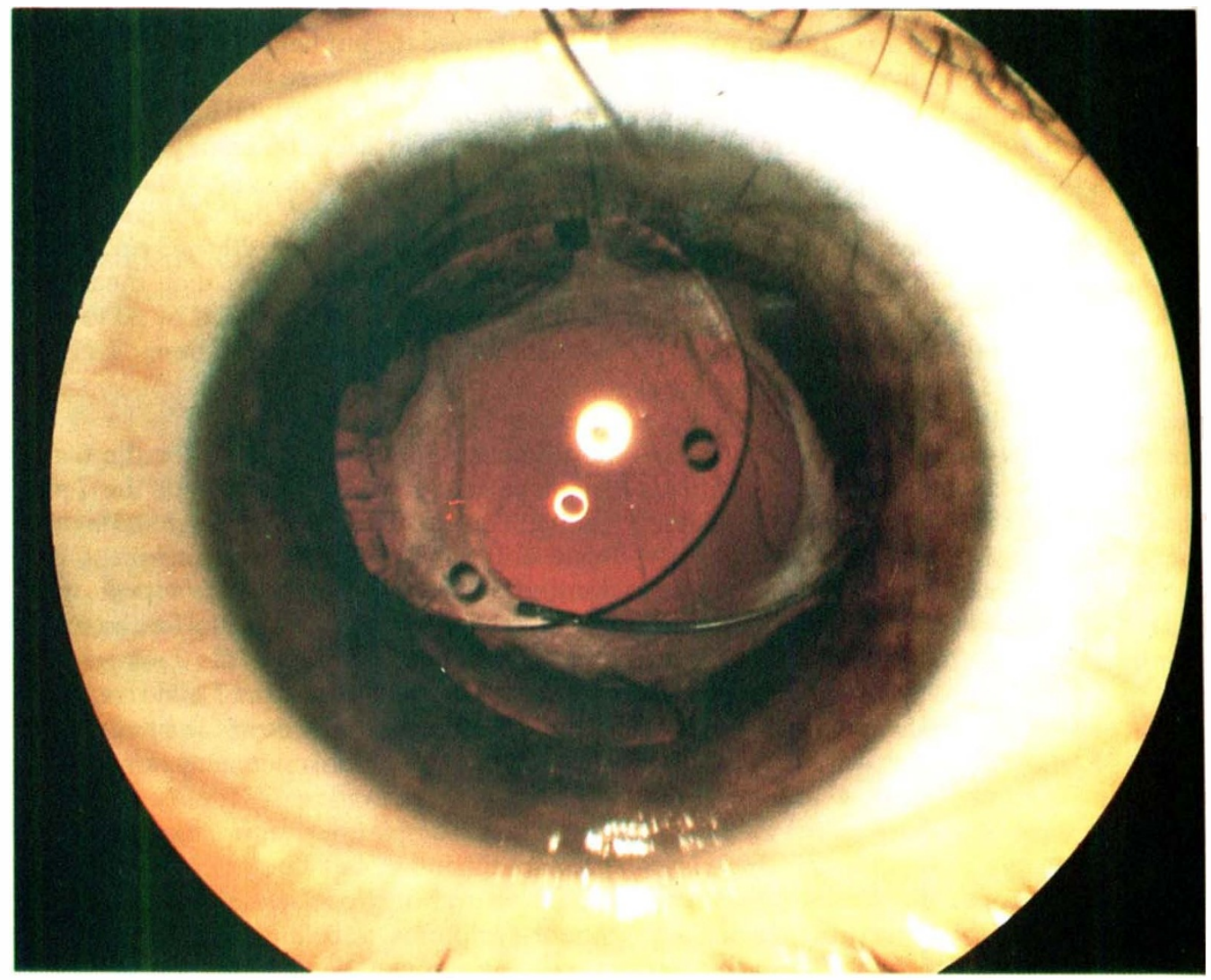

Fig. 1. Patient with decentred $6 \mathrm{~mm}$ optic implant and dialling holes visible in the pupil.

illumination, and 11 patients $(37 \%)$ had dialling holes or the edge of the IOL visible during dim illumination. In the $7 \mathrm{~mm}$ group no patients had dialling holes or the edge of the IOL visible during bright illumination and only one patient $(3 \%)$ had dialling holes visible during dim illumination. This differ- ence between the two groups was significant $(\mathrm{p}=0.0006)$.

How many of these patients with dialling holes in the pupil had symptoms? In the $6 \mathrm{~mm}$ group three of the 11 patients had symptoms: two had ghosting of images and one had glare, and in the $7 \mathrm{~mm}$ group the single patient com-

Table I Summary of results

\begin{tabular}{|c|c|c|c|c|}
\hline $\begin{array}{l}\text { Number of patients } \\
\text { and implant size }\end{array}$ & $\begin{array}{l}\text { Number of patients } \\
\text { with symptoms }\end{array}$ & $\begin{array}{c}\text { Mean } \\
\text { pupil size }\end{array}$ & $\begin{array}{c}\text { Mean } \\
\text { decentration }\end{array}$ & $\begin{array}{c}\text { Number of patients } \\
\text { with dialling } \\
\text { holes in pupil }\end{array}$ \\
\hline $6 \mathrm{~mm} \mathrm{n}=29$ & $6(21 \%)$ & $\begin{array}{l}2.71 \mathrm{~mm} \text { (in light) } \\
5.0 \mathrm{~mm} \text { (in dark) }\end{array}$ & $0.82 \mathrm{~mm}$ & $\begin{array}{r}7 \text { (in light) } \\
11 \text { (in dark) }\end{array}$ \\
\hline $7 \mathrm{~mm} \mathrm{n}=35$ & $5(14 \%)$ & $\begin{array}{l}2.60 \mathrm{~mm} \text { (in light) } \\
4.8 \mathrm{~mm} \text { (in dark) }\end{array}$ & $0.74 \mathrm{~mm}$ & $\begin{array}{l}0 \text { (in light) } \\
1 \text { (in dark) }\end{array}$ \\
\hline $\begin{array}{l}\text { Statistical significance } \\
\text { of difference between } \\
\text { the two groups }\end{array}$ & N/S & $\mathrm{N} / \mathrm{S}$ & $\mathrm{N} / \mathrm{S}$ & $p=0.0006$ \\
\hline
\end{tabular}

$\mathrm{N} / \mathrm{S}=$ not significant . 


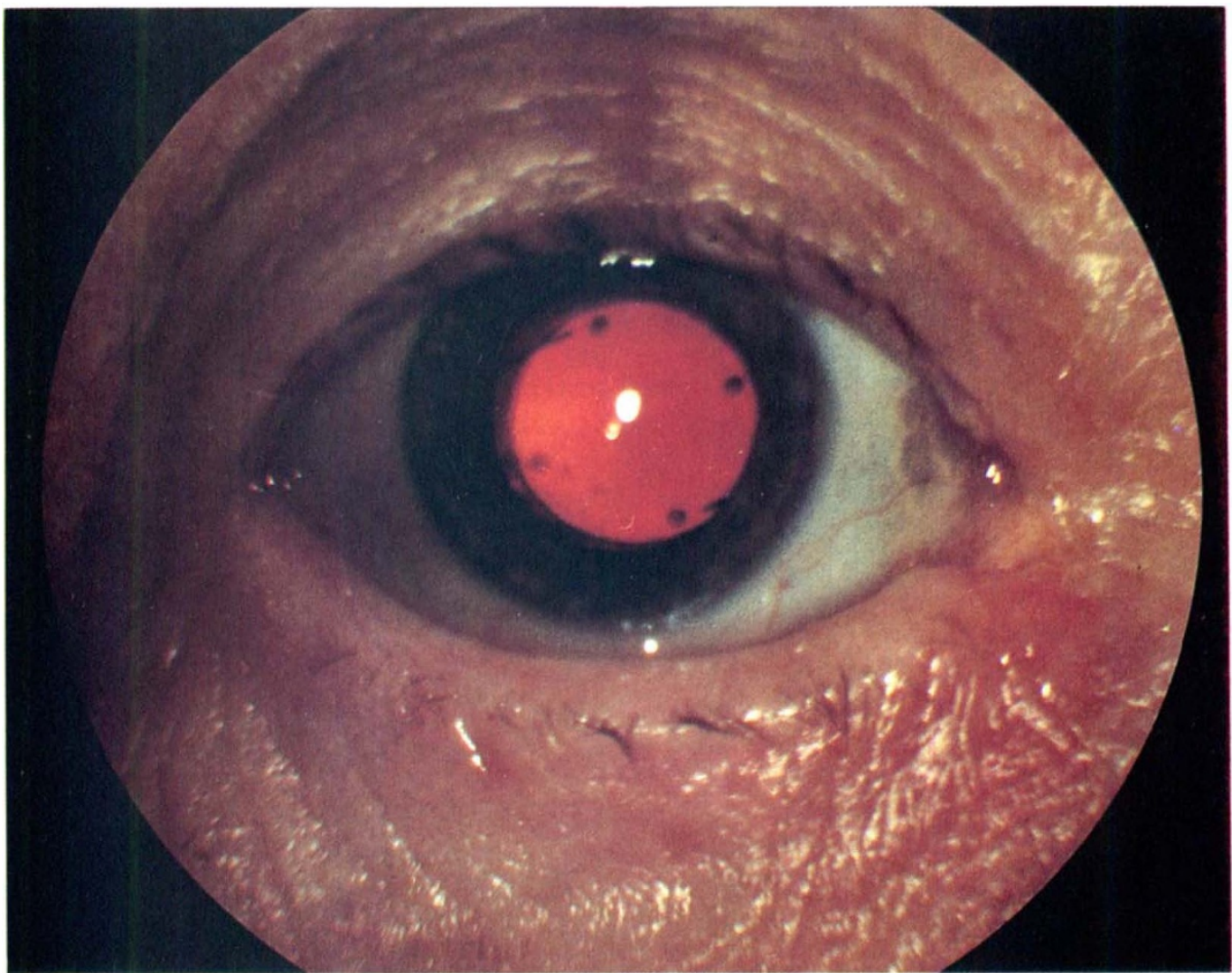

Fig. 2. Patient with a well-centred $6 \mathrm{~mm}$ optic implant whose dialling holes are easily visible when the pupil is dilated.

plained of glare. Figure 1 shows one of the patients with a $6 \mathrm{~mm}$ IOL who had dialling holes visible in the pupil and complained of ghosting of images.

The main results are summarised in Table $\mathrm{I}$.

\section{Discussion}

Recently there have been a number of reports of patients with visual aberrations related to the presence of dialling holes in the pupil. Two papers in the Journal of Cataract and Refractive Surgery (July 1987) ${ }^{1,2}$ report a total of nine patients with problems. The symptoms reported included monocular diplopia, glare, haloes, and rings of lights. These symptoms were most prominent in conditions of dim illumination such as night driving or in the presence of an oblique source of illumination. One of these was a 58 year old airline pilot whose perfectly centred $6 \mathrm{~mm} 4$ dialling hole
IOL, similar to the one shown in Fig. 2, had to be replaced with one without dialling holes because of problems with monocular diplopia and glare at night. However these papers were just isolated case reports and gave no idea of the likely incidence of these problems in a normal surgical practice.

Our study has shown that dialling holes and lens edge are frequently seen in the pupil in patients with a $6 \mathrm{~mm}$ IOL and rarely seen in patients with a $7 \mathrm{~mm}$ IOL, and that this difference is significant. However not all the patients who had dialling holes visible in the pupil had symptoms. There are three factors which may explain this. It may be that our patients, even when specifically asked, are not noticing small degrees of visual aberrations because, as a group, they are not visually demanding. In addition, as we are still operating on a relatively old age group, many of 


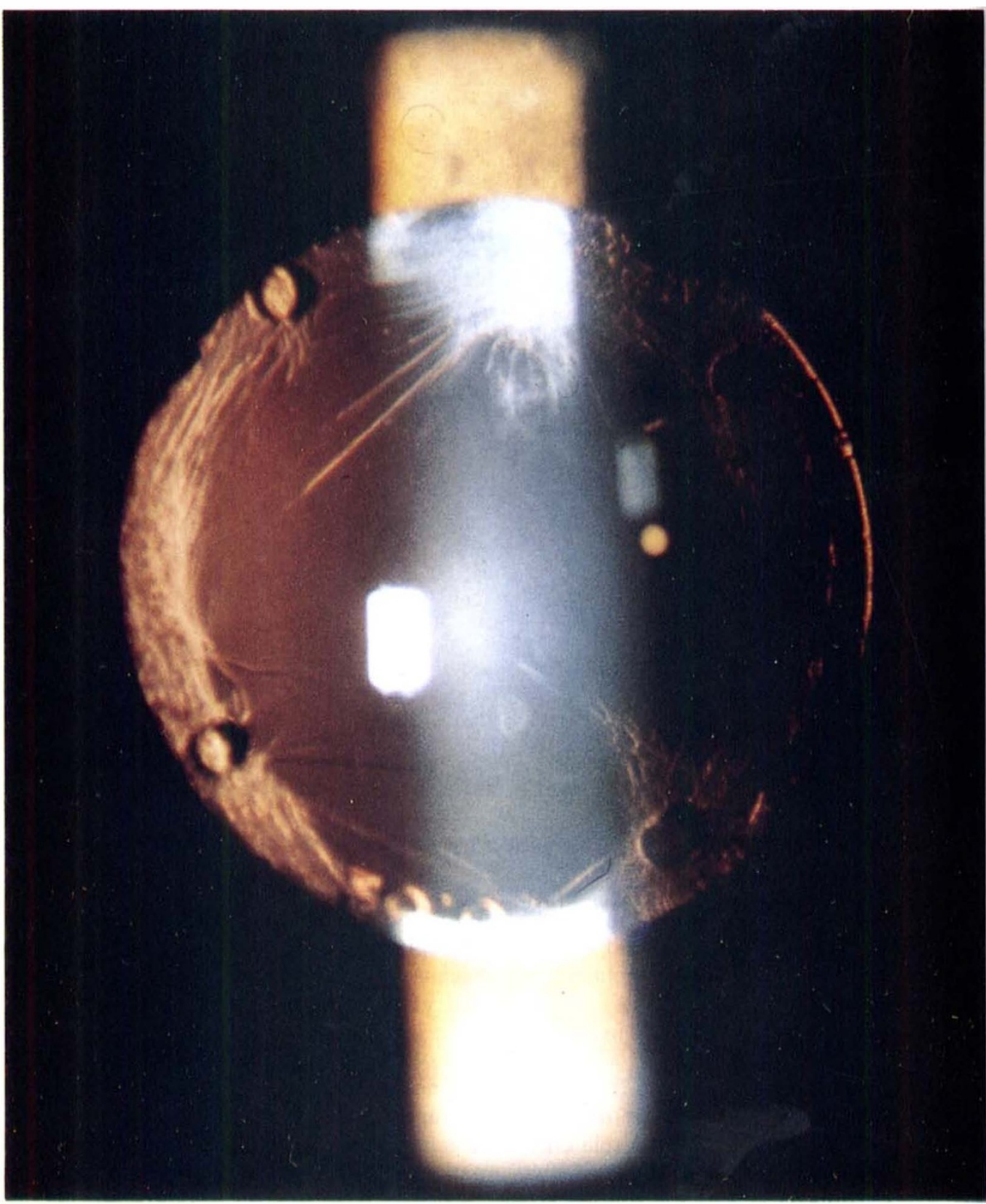

Fig. 3. Patient with the dialling holes of the $6 \mathrm{~mm}$ optic implant occluded by posterior capsular opacity.

our patients are not exposed to the lighting conditions which seem to make these visual aberrations more obvious such as night driving where isolated bright lights are presented to the eye against a background of generally dim illumination. Finally there may be relative opacity of the posterior capsule behind the dialling holes that are in the pupil which effectively occludes them (Fig. 3).

Our study has also shown that there was no significant difference between the incidence of visual aberrations in the two groups despite the higher incidence of dialling holes in the pupil of the $6 \mathrm{~mm}$ group. This may be due to 
factors which increase the incidence of symptoms in the $7 \mathrm{~mm}$ group such as the difference inlens design, which could give more frequent minor posterior capsule opacity (implants with laser ridges are thought to have a higher incidence of posterior capsule opacification when compared with convex posterior surface implants,$\left.{ }^{5,6}\right)$ or perhaps internal reflections from the laser ridge of the $7 \mathrm{~mm}$ implant. Alternatively it may be that the relatively small numbers of patients in each of the groups masks any real difference in the incidence of visual aberrations in the two groups.

Certainly our experience of individual cases is that it is the $6 \mathrm{~mm}$ implant with four dialling holes which may cause problems. Within the past two years we have had three patients, not in our consecutive series of study patients, who have had problems related to dialling holes in the pupil.

The degree of decentration of the implant was similar in the two groups and is similar to previous reports of decentration in the literature. ${ }^{3,4}$ However it is obvious that the same amount of decentration is more likely to place a dialling hole in the pupil with a $6 \mathrm{~mm}$ optic implant. Although our study compared implants with different optic sizes, it is actually the diameter of the optical clear zone between the dialling holes which is crucial. ${ }^{2}$ We found the average pupil diameter under dim illumination was about $5 \mathrm{~mm}$ which is similar to the findings of a previous study where average pupil size in the dark, was compared to age. The mean pupil size in the dark gets smaller with age but even by the age of 65 years the pupil size is still over $5 \mathrm{~mm}$. This would mean that dialling holes on the $6 \mathrm{~mm}$ implant might well be visible even if it is perfectly centred, as the optical clear zone between the dialling holes is only $4.4 \mathrm{~mm}$ in diameter. The $7 \mathrm{~mm}$ implant used in this study, as well as having fewer and smaller dialling holes, has the advantage of a larger optical clear zone of $5.36 \mathrm{~mm}$ in diameter which moves the holes further away from the pupil centre. This also allows a better view of the peripheral fundus which would be an advantage in the case of retinal detachment surgery and peripheral laser treatment.

In conclusion our study has shown that implant components such as dialling holes or the edge of the lens are more likely to be visible in the pupil if a $6 \mathrm{~mm}$ implant with dialling holes in the optic is used when compared to a $7 \mathrm{~mm}$ implant. The relatively small size of our series did not demonstrate that this increased the incidence of visual aberrations in the $6 \mathrm{~mm}$ implant group, but our overall clinical experience suggests that this is probably the case. It seems likely that in the future we will be operating on many younger patients who are still working and who are more visually demanding. To minimise the chances of implant components causing visual aberrations we would therefore recommend an implant design that has an optical clear zone of at least $6 \mathrm{~mm}$ so that the pupil covers the lens edge and dialling holes in dim illumination with a margin of safety in case of implant decentration.

\section{References}

${ }^{1}$ Apple DJ, Lichtenstein SB, Heerlein K, Letchinger SL, Park RB, Brems RN, Piest KL: Visual aberrations caused by optic components of posterior chamber intraocular lenses. J Cataract Refract Surg 1987, 13: 431-5.

${ }^{2}$ Landry RA: Unwanted optical effects caused by intraocular lens positioning holes. J Cataract Refract Surg 1987, 13: 421-3.

${ }^{3}$ Hansen SO, Tetz MR, Solomon KD, Borup MD, Brems RN, O'Morchoe DJC, Bouhaddou O, Apple DJ: Decentration of flexible loop posterior chamber intraocular lenses in a series of 22 postmortem eyes. Ophthalmology 1988, 95: 344-9.

${ }^{4}$ Gaskell A and Baines PS: Comparison of flexible loop posterior chamber lens implant centration following intercapsular versus extracapsular cataract surgery. Eur J Implant Refract Surg 1988, 6: 88-91.

${ }^{5}$ Downing JE: Long-term discission rate after placing posterior chamber lenses with the convex surface posterior. J Cataract Refract Surg 1986, 12: 651-4.

${ }^{6}$ Sterling S and Wood TO: Effect of intraocular lens convexity on posterior capsule opacification. $J$ Cataract Refract Surg 1986, 12: 655-7.

${ }^{7}$ Loewenfeld IE: Pupillary changes related to age. In Thompson HS ed. Topics in Neuro-ophthalmology, Baltimore: The Williams \& Wilkins Co 1979. 